\title{
A Proposal for a New Variable Leakage Flux Motor with Interpolar Gap and Permanent Magnets
}

\author{
Shin Kusase ${ }^{*, * a a)}$ Member, Kazumi Kurihara* ${ }^{*}$ Senior Member
}

(Manuscript received Jan. 23, 2017, revised July 3, 2017)

\begin{abstract}
Recently, interior permanent magnet motors (IPMs) or motors with field winding have been investigated from a viewpoint of magnetic field control. IPMs have an advantage of field weakening; however, their overall flux passing the stator core is not sufficiently suppressed. On the other hand, motors with field winding can control a wide range; however, they need the field windings and are the complicated shape and heavy. In this paper, a new structure of hybrid field motor without a field winding is proposed, whose rotor has regular salient poles arranged with interpolar gap and permanent magnet. In addition, this interpolar gap and permanent magnet motor (IGPM) is investigated along with its characteristics. By means of some basic equations related to flux, torque, and FEA, it is clarified that IGPM is more appropriate for field weakening control than IPM. In addition, we found that the proposed IGPM has yielded successful FEA and experimental results by preliminary prototype.
\end{abstract}

Keywords: hybrid field motor, variable field, bypass yoke core

\section{Introduction}

The surface permanent magnet motor (SPM) has advantageous features of a simple structure and high performance. However, it is not easy to adjust the magnetic field flux. Recently, IPM spreading remarkably has the feature which can weak the main magnetic flux by using the magnetic field by the magneto motive force (MMF) of armature current, even though the rotor has similar configuration to the SPM.

Nowadays the IPM becomes a popular motor, especially for wider variable-speed applications, such as hybrid vehicles, which need a high torque even at high speeds ${ }^{(1)(2)}$.

However, in fact, even in the IPM, it is known that high order components of magnetic flux still remain much in the armature core in the high-speed/low-torque region when the field weakening control is applied to the IPM ${ }^{(3)}$. Many researchers have reported about variable magnetic field systems ${ }^{(4)-(7)}$.

For example, in (7), although it is investigated and verified that varying the magnetic field widely can realize by using a mechanical actuator, the mechanism is too complicated for the severe endurance requirement in actual applications.

In addition, although the motor proposed in (8) has field and another windings which generate exciting power to supply to the field winding, many parts used in the motor complicate the manufacturing of the motor.

In (9) (10), Variable Leakage Flux (VLF) motor is proposed. The VLF has an additional leakage path which is narrow path linked two tops of adjacent poles, then it varies the

\footnotetext{
a) Correspondence to: Shin Kusase. E-mail: shin_kusase@ denso. co.jp

* Ibaraki University

4-12-1, Hitachi, Ibaraki 316-8511, Japan

** DENSO CORPORATION

1-1, Kariya, Aichi 448-8661, Japan
}

main flux by changing its own magnetic saturation state, the range of variability of magnetic pole flux is not so wide, it remains in the range 100-150(\%). If VLF's additional leakage path is enlarged, then variability of flux cannot be derived since high saturation of leakage path requires huge Iq.

This study aims to suppress the residual magnetic flux to near zero in the field weakening region, aiming at iron loss reduction, in the type of hybrid variable field motor without a magnetic field winding. Although superior performance than IPM's should be pursued, this first stage for now, clarification the basic principle of enlarging the variability of the field magnetic flux is focused.

In this paper, principle and characteristics of this motor are clarified by FEA and experiment. First, theoretical equations for torque and the variability of the field flux are described. Second, FEA is carried out to validate the equations. Last, the experimental results using preliminary prototype are presented for comparison with the torque characteristic simulated by FEA.

\section{Basic Theory of Torque and Variability of Magnetic Field Flux}

2.1 Structure of Proposed Motor Figure 1 shows a cross section of the motor proposed in this paper. The rotor structure is characterized by gear-like poles, with embedded

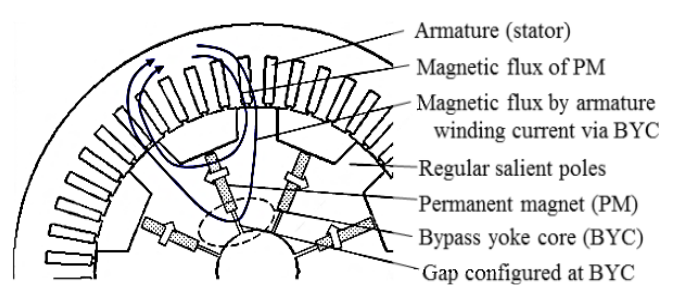

Fig. 1. Proposed topology of magnetic circuit of the IGPM motor 
PMs and a bypass yoke core (BYC). Two magnetic flux paths are arranged in the rotor core. One is a flux path by one PM that passes from pole to pole, emerging via the PM, and the other is a flux path by armature current that passes via the BYC and the gap, emerging by the armature current. We call this motor an interpolar gap permanent magnet (IGPM) motor.

The PM is magnetized in the circumferential direction. About the air gap in the bypass core, the length is less than the width of the PM. In both IPM and VLF, the PM is buried shallowly beneath a pole center, but in IGPM, the PM is buried between the adjacent two poles. Although the basic concept which has variable MMF (5), (6) to obtain variability for the main magnetic flux is the same as for a conventional hybrid field, it is different way of adding a changeable electromagnet MMF to the fixed MMF of the PM. Therefore, the way has a new alternative feature of the IGPM, using the MMF by armature current as an excited power source of main magnetic flux. That is, the field MMF generated by the armature current achieves variability in the main magnetic flux.

2.2 Torque Equation and Contribution of the BYC For a synchronous PM motor, in general, the torque $T$ can be expressed as follows:

$$
\frac{T}{P_{n}}=\Psi_{a} I_{a} \cos \beta+\frac{1}{2}\left(L_{q}-L_{d}\right) I_{a}^{2} \sin 2 \beta \ldots \ldots \ldots
$$

Where,

$$
\begin{aligned}
& \Psi_{a}=\Psi_{e m}+\Psi_{e c}=\Psi_{e m}-L_{e c} I_{a} \sin \beta \ldots \ldots \ldots \ldots \ldots \ldots \ldots \ldots \ldots \ldots \ldots \ldots \ldots \ldots \ldots \ldots \ldots \ldots \ldots \\
& \because \Psi_{e c}=L_{e c} I_{d} \ldots \ldots \ldots \ldots \ldots
\end{aligned}
$$

From (1) and (2),

$$
\begin{aligned}
\frac{T}{P_{n}}= & \Psi_{e m} I_{a} \cos \beta-\frac{1}{2} L_{e c} I_{a}^{2} \sin 2 \beta \\
& +\frac{1}{2}\left(L_{q}-L_{d}\right) I_{a}^{2} \sin 2 \beta \ldots \ldots
\end{aligned}
$$

Where,

$P_{n} \quad$ Number of pole pairs

$I_{a} \quad$ Armature current (A)

$\psi_{a} \quad$ Main flux linkage of armature $(\mathrm{Wb})$

$\psi_{e m} \quad$ Flux linkage by PM (Wb)

$\psi_{e c} \quad$ Flux linkage by MMF of armature current $(\mathrm{Wb})$

$L_{d} \quad$ Inductance of the rotor direct-axis $(\mathrm{H})$

$L_{q} \quad$ Inductance of the rotor quadrature-axis $(\mathrm{H})$

$L_{e c} \quad$ Inductance of bypass path $(\mathrm{H})$

$\beta \quad$ Phase angle $\left({ }^{\circ}\right)$ defined as zero when $\dot{I}_{a}$ is just on $q$-axis.

In Eq. (4), the first term is the PM torque. The second term is the torque arising from the armature MMF via the BYC. The third term is a reluctance torque, which is due to the saliency.

The Eq. (4) results in the following:

First, when $0<\beta<90\left(^{\circ}\right)$, the second term is negative. The third term is positive when $L_{q}>L_{d}$ (reverse saliency pole), or it is negative when $L_{q}<L_{d}$ (regular saliency pole).

Second, when $-90\left(^{\circ}\right)>\beta>0$, the second term is positive. The third term is negative when the $L_{q}>L_{d}$ (reverse saliency pole), or it is positive when the $L_{q}<L_{d}$ (conventional regular saliency pole).

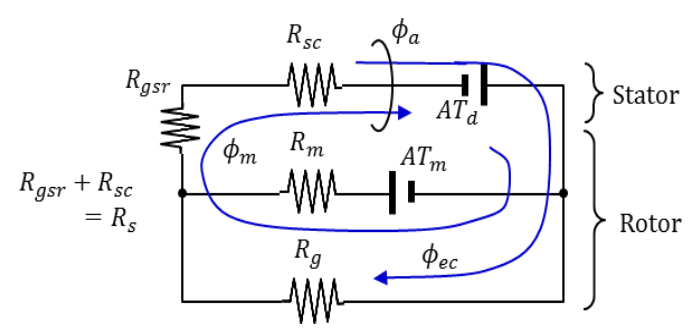

Fig. 2. Field fluxes and MMFs of the IGPM's magnetic circuit

From this case study, the design specifications to be considered in the IGPM are as follows:

The pole should have regular saliency. Next, the phase angle $\beta$ of armature current $\dot{I}_{a}$ should be in negative range.

Under these conditions, adding the three torque components give high torque in the IGPM.

2.3 Magnetic Circuit Equation for Flux Variability Contributed by the BYC Circuit Figure 2 shows a simplified model of the IGPM magnetic circuit. Focusing on the flux flows into the rotor pole cores, the fluxes by two magnetic flux sources are flowing through the cores. One is magnetic flux $\phi_{e m}$ flowing through the PM, and the other is magnetic flux $\phi_{e c}$ flowing through the bypass core BYC.

The magnetic flux $\phi_{e m}$ arises from the MMF $A T_{m}$ by the $\mathrm{PM}$, and $\phi_{e c}$ arises from the $d$-axis MMF shown as $A T_{d}$, and the main magnetic flux $\phi_{a}$ is interlinked in the armature. These three magnetic fluxes flowing in the magnetic circuit of IGPM are shown in Fig. 1.

Although $\phi_{e m}$ is kept constant, $\phi_{a}$ can be changed so that $\phi_{e c}$ has variability, which is those sum totals.

Where,

$A T_{d} \quad$ Direct-axis MMF in the armature

$A T_{m} \quad$ PM's MMF in the rotor

$\phi_{a} \quad$ Main magnetic flux

$\phi_{e c} \quad$ Magnetic flux flowing through BYC

$\phi_{e m} \quad$ Magnetic flux flowing through PM

$R_{s c} \quad$ Reluctance of the stator core

$R_{g s r} \quad$ Reluctance of the rotor-stator airgap

$R_{s} \quad$ Reluctance of the stator side, total $\left(R_{s c}+R_{g s r}\right)$

$R_{m} \quad$ Reluctance of the air space in the PM's slot

$R_{g} \quad$ Reluctance of the gap in the BYC

The equation for the main flux $\phi_{a}$ derived from the circuit model in Fig. 2 is as follows,

$$
\phi_{a}=\phi_{e c}+\phi_{e m}=\frac{R_{g} A T_{m}+\left(R_{m}+R_{g}\right) A T_{d}}{R_{m} R_{s}+R_{s} R_{g}+R_{g} R_{m}} \cdots \cdots
$$

where, from a practical design point of view;

$$
\begin{aligned}
& R_{s}, R_{g} \ll R_{m} \\
& \phi_{a}=\frac{1}{R_{g}+R_{s}}\left(\frac{R_{g}}{R_{m}} A T_{m}-N \cdot I_{a} \sin \beta\right) \ldots \ldots \ldots \\
& A T_{d}=\mathrm{N} \cdot I_{d}=-N \cdot I_{a} \sin \beta \ldots \ldots \ldots \ldots \ldots \\
& N \text { Turns of the armature winding/pole/phase. }
\end{aligned}
$$

In Eq. (6), the magnetic flux is formed from two different terms, one is the constant part of the permanent magnet shown by the first term, and the other is the MMF by the armature current as a function expressed by the variable current and the phase angle $\beta$ shown in the second term. Here, 
$R_{g}$ manages first term. If $R_{g}$ is nearly zero, the MMF ATm caused by the permanent magnets gives small $\phi_{a}$. This is the reason why a certain length of gap must be maintained for the gap at the BYC.

Main object in this paper is to enlargement of variability and to realize nearly zero state magnetic flux in the stator core without a field winding. As an answer, since IGPM has a unique structure different from other things, it can actually be designed based on Eq. (6). Unlike others, IGPM has wide bypass with gap near the rotor center. The inductance Lec of that portion acts on the field weakening like $L d$ of the IPM, then IGPM has some merits in variability of flux.

First, field weakening is easier because of linear permeability of wide bypass with gap, so enormous flux can leak flux, or also can add flux by field intensifying MMF without magnetic saturation. Second, since bypass has gap, MMF of permanent magnet can be kept adequate level not be low. Third, $L q$ can be made small, since short pole arc, that is brought from absence of bypass near the magnetic pole sides. So, basically Eq. (6) is peculiar and useful in designing of the IGPM.

\section{Comparison of IGPM and IPM for Torque and Field Flux Weakening Characteristics by FEA}

3.1 Analysis Models and Conditions Since the fundamental principles of the IGPM were clarified as $T-\beta$ torque Eq. (4), and varying flux Eq. (6), here those expressions are ascertained analytically by 2-D FEA (JMAGDesign ver. 14.0).

Here, the newly designed rotor based on the above principles has regular magnetic saliency that originates from the gear-like projecting poles and wide and deep interpolar cavities on the rotor outer surface.

Plate-like PMs are buried radially at the interpolar gap, and bypass yoke cores (BYC) which divert the magnetic field flux to the PM's slot are arranged radially inside the PMs. The BYC has a gap much less than the PM's slot width.

Figure 3(a) shows one fundamental IGPM model for FEA, considering these design factors. On the other hand, Fig. 3(b) is an IPM model for comparison.

The IGPM and IPM have the same design for the stator; the rotors have the same outer diameter, number of poles and PM material. The width of the PM for the IGPM is thinner than one for the IPM, although they have the same design restrictions, which are in keeping with the width without permanent demagnetization. Detailed specifications are given in Table 1.

\subsection{Torque Characteristics of the IGPM and IPM}

Under these conditions for analysis, we verified by comparing with the IPM whether the relationship between the torque $T$ and $\beta$ are related by Eq. (4). According to Eq. (4), the PM torque originating from $\psi_{\mathrm{em}}$ is affected by the function, $\cos \beta$. Also, the field flux torque component originating from $\psi_{e c}$ through the bypass circuit, and the reluctance torque component originating from $\left(L_{q}-L_{d}\right) I_{a}^{2}$ are affected by $\sin 2 \beta$.

The results analyzed by FEA are shown in Fig. 4 . The IGPM discloses the periodicity of $180\left(^{\circ}\right)$, and has a certain vertical shift from zero point. Those are the same tendencies of the Eq. (4) including the functions: $-\sin 2 \beta$ and $\cos \beta$.

The maximum motor torque of the IPM is around $\beta=$

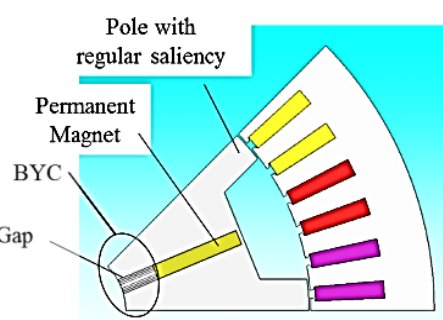

(a) IGPM

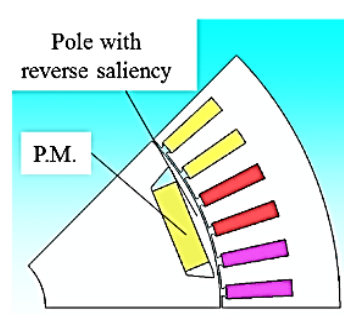

(b) IPM
Fig. 3. Models for comparison

Table 1. Specification of analytical models

\begin{tabular}{c|c|c}
\hline & IGPM & IPM \\
\hline Current & Phase current $150(\mathrm{~A})$ (RMS) \\
\hline Stator / Slots & D 120 x L66 (mm) / 48 slots. \\
\hline Windings & Full pitch, Distributed Y, 6-turns/slot \\
\hline Poles & $8 \mathrm{P}$ \\
\hline PMs & $2.4 \times 14.6 \times 66(\mathrm{~mm})$ & $4.8 \times 14.6 \times 66(\mathrm{~mm})$ \\
\hline \multirow{2}{*}{ Gaps } & N36Z (Shin-Etsu Chemical Co.) \\
\hline & In the BYC; $1.2(\mathrm{~mm})$ & \\
\hline
\end{tabular}

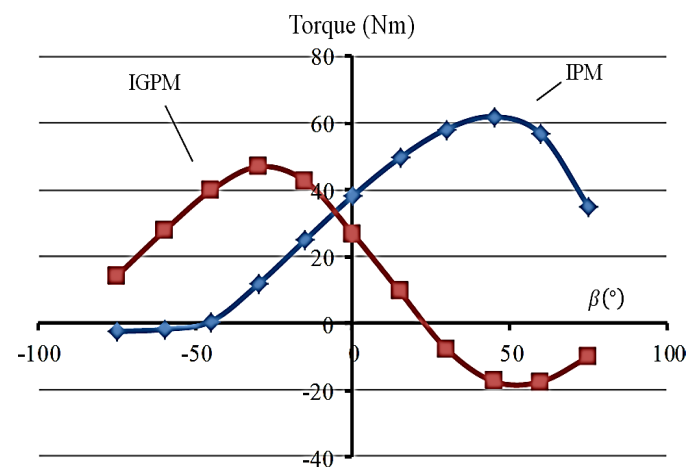

Fig. 4. $T-\beta$ characteristics of the IGPM and IPM

$+50\left(^{\circ}\right)$. For the IGPM, it is nearer $\beta=-30\left(^{\circ}\right)$. As represented by Eq. (4), it is confirmed for the IGPM to operate as a motor in the negative region of $\beta$. In this case, the IGPM's maximum torque is somewhat small. As one of reason of lower torque of IGPM, amount of IGPM's permanent magnet is about half of IPM. Since we think the final output target of IGPM is greater than IPM, continuous investigation will be held from now on.

3.3 Characteristics in Weakening the Magnetic Flux Passing Through the Stator Core In this section the magnetic flux passing through the armature stator core of the IGPM is compared with one of the IPM.

Figure 5 shows the characteristics at the weakening field with respect to the d-axis of the magneto motive force $A T_{d}$ $\left(=N \cdot I_{d}\right)$ for the IGPM and IPM. Since the IGPM has a bypass circuit, BYC, it should be able to significantly reduce the magnetic flux when poles are given contrary MMF of the armature. On that basis, analysis was used to find the best conditions where the magnetization direction of the armature MMF is set opposite to the rotor pole, i.e. the armature current angle is $\beta=90\left(^{\circ}\right)$.

Figure 5(a) shows the comparison of IGPM and IPM with each interlinkage flux which passes the iron core and links 


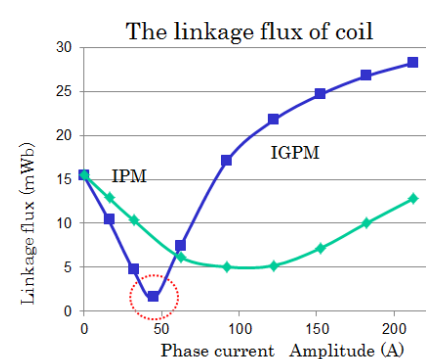

(a) Interlinkage flux $\Phi \mathrm{a}$

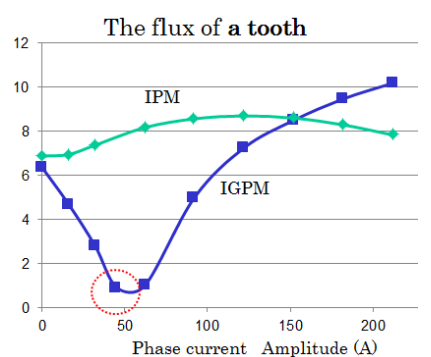

(b) Tooth flux
Fig. 5. Comparison of the flux under the condition of a weakening field in the IGPM and IPM at $\beta=90\left(^{\circ}\right)$

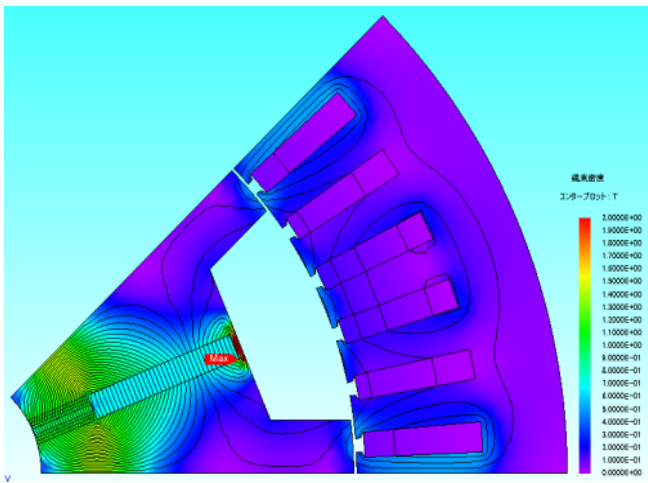

(a) IGPM $\beta=90\left({ }^{\circ}\right)$, current amplitude 45 (A) PM Size; $14.5 \times 2.4(\mathrm{~mm})$

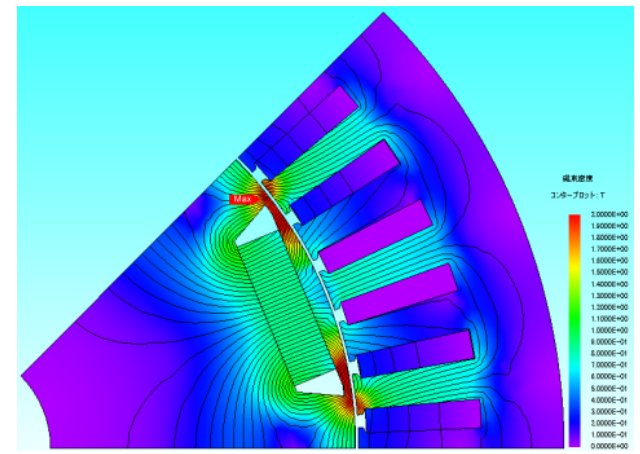

(b) IPM $\beta=90\left(^{\circ}\right)$, current amplitude 92 (A) PM size; $14.5 \times 4.4(\mathrm{~mm})$

Fig. 6. Comparison of weakening field in IGPM and IPM (flux flowing into the teeth)

to coils. There are valleys about both curves, but especially IGPM has lower flux and lower Id. Figure 5(b) shows the average of the magnetic flux which passes the iron core tooth of the armature. There is a valley where the minimum flux is given by the minimum $A T_{d}$. For an example, there is about $-95(\%)$ drops. On the other hand, regarding this decreasing characteristics, the magnetic flux in the IPM drop only $-23(\%)$.

Moreover, as shown in Figs. 6(a) and (b), the contour of the magnetic flux density shows a big difference.

\section{Verification of the Effect of BYC and the Gap from the FEA Models}

As mentioned in the previous sections, one of the features of the IGPM is to have a BYC with a gap in the inner rotor portion. A simulation (FEA, JMAG-Design ver. 14.0) was done, focusing on this regional bypass circuit.

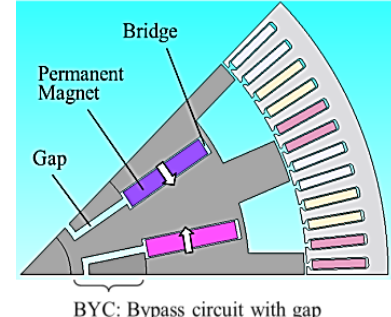

(a) Prototype model

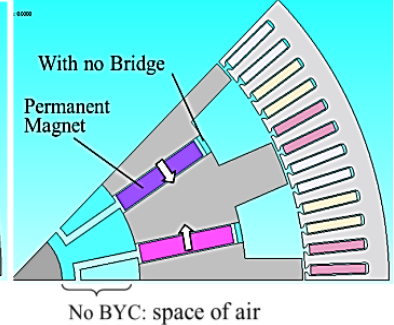

(b) Extra model with no BYC
Fig. 7. FEA models to confirm the effect of the BYC

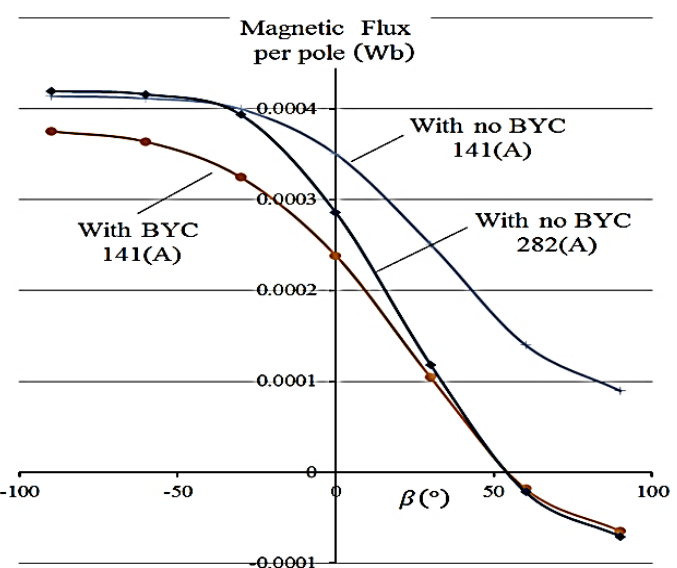

Fig. 8. FEA results for the presence or absence of a BYC

In Figs. 7(a) and (b), 2-D FEA models are prepared to investigate the difference between the presence or absence of a BYC and a gap. Here, Fig. 7(a) has the same specifications as the prototype described later; details are given in TABLE II. The other analysis model shown in Fig. 7(b) is also a 2-D FEA model with the same dimensions and same design specifications. In other words, the model in Fig. 7(b) having no $\mathrm{BYC}$ is one of a conventional PM motor.

In this simulation, It should be mentioned that the shapes of FEA models of Figs. 7(a) and 7(b) are designed in the same. However, in calculation conditions, the BYC's material is changed from steel to air, so Fig. 7(b)'s BYC region is calculated with the absence of an iron BYC. Figure 8 shows calculated results. The BYC effect that the magnetic pole flux is suppressed to zero easily using BYC can be seen. Here, the magnetic pole flux is whole flux at the entrance and exit path of extreme surface of rotor covering one pole pitch range, which was derived by FEA. It can be plotted as DC magnetic flux without alternating, so we can grasp of the direction of the magnetic pole flux totally.

Three cases are calculated for the variable characteristics of the magnetic field flux by changing current phase angle $\beta$.

As shown in Fig. 8, the upward curve in the three is for a BYC with a current of amplitude 141 (A) injected into the armature coil.

The second is without a BYC and with a current of amplitude 141 (A). And downward curve is without a BYC and with a current of amplitude 282 (A).

With no bypass circuit and an armature current of 141 (A), for example, even if $\beta$ is set to plus $90\left(^{\circ}\right)$, with a magnetic field of the opposite orientation, the motor cannot suppress the magnetic pole flux to zero. 
In increasing the armature current to around $282(\mathrm{~A})$, the pole flux can be suppressed to zero at around $\beta=55\left(^{\circ}\right)$. However, if it has a bypass circuit, it is easy to suppress the flux to zero with smaller current 141 (A) at the same angle.

\section{Experimental Verification-torque Character- istic Versus the Phase Angle by Preliminary Prototype}

5.1 Specifications of Prototype For verification the IGPM's basic characteristics, the IGPM's torque was calculated by FEA and tested with the prototype. It was designed according to the theory given previously.

The detailed specifications are shown in Table 2.

The trial product was manufactured using alternator parts for vehicles currently being mass-produced where the housing and the armature stator were reused Figs. 9 and 11 shows the manufactured rotor of the IGPM.

5.2 Verification of the $\boldsymbol{T}-\boldsymbol{\beta}$ Characteristics by Experiment As described above, the basic principle of Eq. (4) is confirmed from the $T-\beta$ characteristics by FEA.

Here, the simulated characteristics are verified experimentally.

First, regarding the experimental method, as shown in Fig. 10, two phases of the armature winding are excited by currents, then the rotor is rotated very slowly, and the torque

Table 2. Specifications of prototype

\begin{tabular}{|c|c|}
\hline & Specifications \\
\hline Stator core & $\begin{array}{l}\text { OD: } 128, \text { ID: } 100, \text { Stack length: } 32(\mathrm{~mm}) \text {, } \\
\text { Core: } 35 \mathrm{H} 250\end{array}$ \\
\hline Rotor core & $\begin{array}{l}\text { OD: } 99.3(\mathrm{~mm}) \text {, Pole: } 16 \text { poles, regular saliency, } \\
\text { arc ratio: } 0.4 \quad \text { Core: } 35 \mathrm{H} 250\end{array}$ \\
\hline $\begin{array}{l}\text { Armature } \\
\text { windings }\end{array}$ & $\begin{array}{l}\text { Full pitch, distributed Y, 4-turns /slot, } \\
\text { total number of slots: } 96\end{array}$ \\
\hline PM & $\begin{array}{l}\text { Equivalent to N36Z (Shin-Etsu Chemical Co.) } \\
\text { Size: } 3.0 \times 16 \times 32(\mathrm{~mm})\end{array}$ \\
\hline Gaps & $\begin{array}{l}\text { At the BYC: } 1.2(\mathrm{~mm}) \\
\quad \text { between the stator and rotor: } 0.35(\mathrm{~mm})\end{array}$ \\
\hline
\end{tabular}

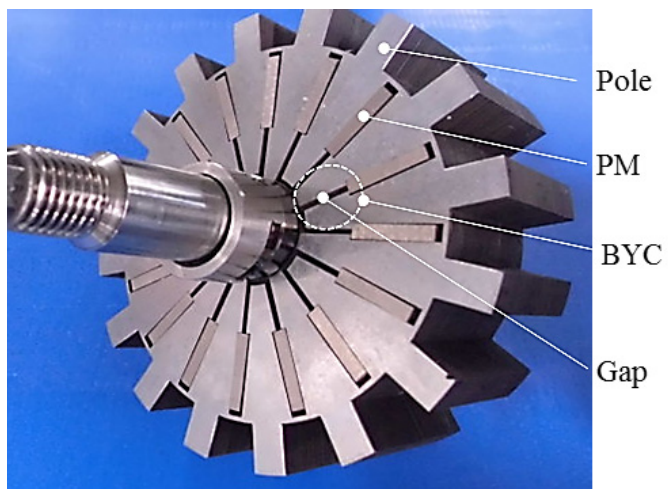

Fig. 9. Preliminary prototype rotor

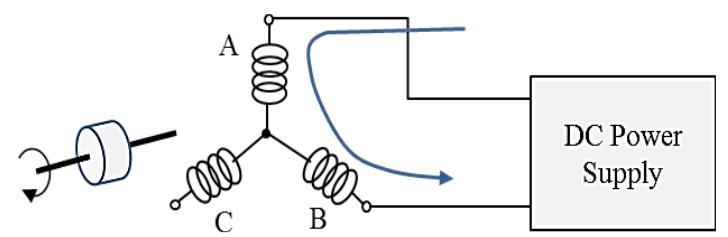

Fig. 10. Wiring diagram for test and angle are measured as shown in Fig. 11. Then the $T-\beta$ plot data was derived.

Other test conditions are shown in Table 3.

The test results are shown in Fig. 12, which are the torque characteristic versus current phase angle $\beta$. The simulation and measured values agree well. And the plotted curve and values show the same tendencies with the Eq. (4) including the functions: $-\sin 2 \beta$ and $\cos \beta$.

There was a little play in the clutch of the testing tool for the IGPM motor, and it is considered that the errors arose in measuring the peak magnitude portion, especially in the negative torque region. The authors suppose that a kind of follow-up in the motoring device is delayed by some play, as a result, the torque is counted lower during that time.

5.3 Verification of Variability of Field Flux To support experimentally wide variability of IGPM's magnetic flux of field pole is investigated using prototype as follows.

The specification and conditions are shown in Tables 2 and 3 , and results are shown in Fig. 13. FEAs and testing were done about line voltage, torque. About magnetic flux of pole, only FEA is done because of its difficulty of measurement. As a result, better agreement was seen about FEA and the testing about line voltage and torque, at least qualitatively.

Table 3. Testing condition and measuring instrument

\begin{tabular}{l|l|l}
\hline & \multicolumn{1}{|c|}{ Testing Conditions } & \multicolumn{1}{c}{ Remarks } \\
\hline Speed & $500(\mathrm{rpm})$ & Restricted by equipment \\
\hline Coil current & DC $100(\mathrm{~A})$ & \\
\hline \multirow{2}{*}{ Torque meter } & Sensor HTM-30NM & $\begin{array}{l}\text { Provided by Takachiho } \\
\text { Seiki Co. }\end{array}$ \\
\cline { 2 - 3 } & Converter TM200 & Sein \\
\hline
\end{tabular}

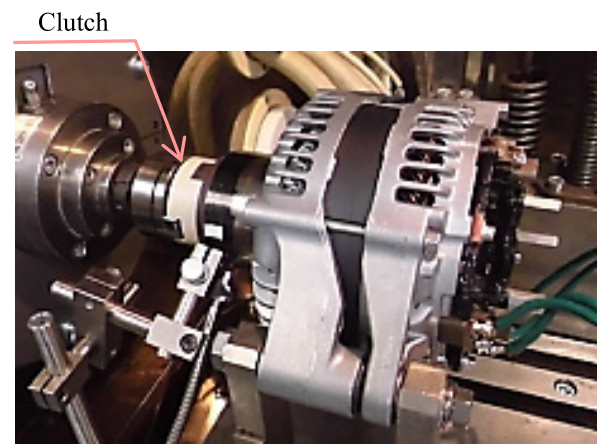

Fig. 11. Installation of the prototype on test bench

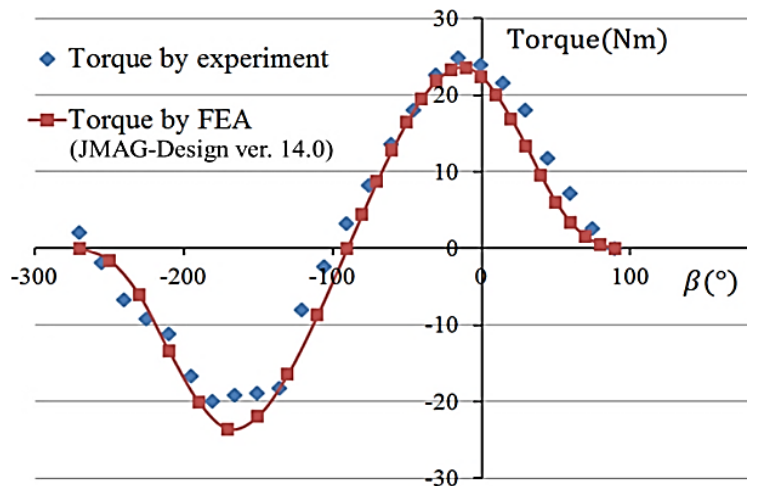

Fig. 12. Comparison of simulation and measured results for torque versus $\beta$ 


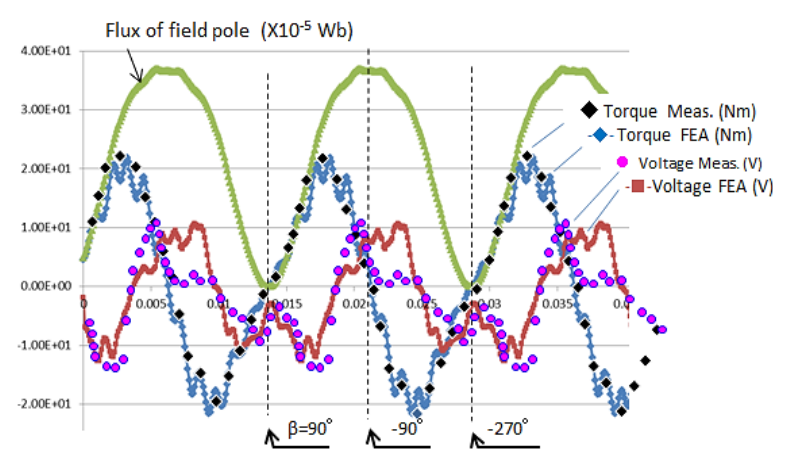

Fig. 13. Fluctuation of the flux of field pole, torque and line voltage (DC current 90A, rotating speed $500 \mathrm{rpm}$ )

Therefore, the authors think that it has verified indirectly that the magnetic flux of field pole is also wavy for the beta shown Fig. 13, and the minimum value of this magnetic field pole correspond to the weakening field corresponding $\beta=90 \mathrm{deg}$, then the magnetic flux of the field magnetic pole is almost zero. Thus, the magnetic flux variable rate is $100 \%$.

\section{Conclusion}

This paper proposes a new structure motor which is one of Variable Leakage Flux (VLF) motor without a field winding, whose rotor has a structure of interpolar gap and permanent magnet (IGPM), and has regular salient poles.

For the rotor of the new magnetic circuit, a basic theory including some equations related to flux and torque is derived, and design key factors focusing field flux weakening are also clarified.

According to the theory, FEA models are designed. And it is clarified that main linkage flux of the stator core can be controlled significantly by changing the flux of the bypass core and interpolar gap, as we expected. It concludes that the IGPM is more appropriate on a field weakening control than the IPM. And we have found that the proposed IGPM has yielded successful FEA simulation and experimental results. In this paper, although the comparison of some characteristics have been done using preliminary prototype of IGPM, next time, the comparisons using optimized prototype of IGPM will be done.

\section{References}

( 1 ) Y. Honda, T. Nakamura, T. Higaki, and Y. Takeda: "Motor Design Considerations and Test Result of an Interior Permanent Magnet Synchronous Motor for Electric Vehicles", IEEE Industry Applications Society Annual Meeting, pp.75-82 (1997)

( 2 ) M.A. Rahman: "IPM Motor Drives for Hybrid Electric Vehicles", IEEElectrical Machines and Power Electronics, pp.109-115 (2007)
( 3 ) K. Yamazaki, S. Ohki, A. Nezu, and T. Ikemi: "Development of Interior Permanent Magnet Motors Reducing Harmonic Iron Losses under Field Weakening Control”, IEEJ Trans. on IAS, Vol.127, No.8, pp.837-843 (2007)

( 4 ) K. Liang, W. Xuhui, X. Shan, and F. Tao: "The Study of Bypass Hybrid Excitation Synchronous Motors with Extended Field-Weakening Capability", Electrical Machines and Systems, ICEMS 2008. International Conference, pp.3627-3631 (2008)

( 5 ) Y. Amara, L. Vido, M. Gabsi, E. Hoang, A. Hamid, B. Ahmed, and M. Lecrivain: "Hybrid Excitation Synchronous Machines: Energy-Efficient Solution for Vehicles Propulsion”, IEEE Trans. Veh. Technol., Vol.58, No.5, pp.2137-2139 (2009)

( 6 ) T. Kosaka, T. Hirose, and N. Matsui: "Brushless Synchronous Machines with Wound-Field Excitation using SMC Core Designed for HEV Drives", International Power Electronics Conference 2010, pp.1794-1800 (2010)

( 7 ) T. Ishi, T. Nosaka, S. Oga, and M. Ohto: "Manufacturing and Control of a Variable Magnetic Flux Motor Prototype with a Mechanical Adjustment Method", IEEJ Trans. IA, Vol.136, No.5, pp.328-335 (2016)

( 8 ) M. Aoyama and T. Noguchi: "Estimation of Rotor Current Based on Mathematical Model of Wound-Field Synchronous Motor Self-Excited by Space Harmonics", Power Electronics, Electrical Drives, Automation and Motion (SPEEDAM), 2014 International Symposium, pp.595-600 (2014)

( 9 ) N. Limsuwan, T. Kato, K. Akatsu, and R.D. Lorenz: "Design and Evaluation of a Variable-Flux Flux-Intensifying IPM Machine", IEEE Trans. on Ind. Appl., Vol.50, No.2, pp.1015-1024 (2014)

(10) A. Athavale, T. Fukushige, T. Kato, C.-Y.1 Yu, and R.D. Lorenz: "Variable Leakage Flux IPMSMs for Reduced Losses Over a Driving Cycle While Maintaining Suitable Attributes for High-Frequency Injection-Based Rotor Position Self Sensing", IEEE Trans. on Ind. Appl. Vol.52, No.1, pp.234-241 (2015)

Shin Kusase (Member) received the B.E. and M.E. degrees from

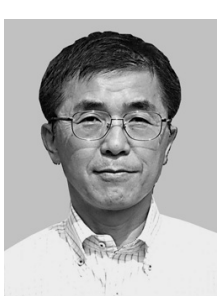
Ibaraki University, Hitachi, Japan, in 1978. He has been with Denso Corporation, Kariya, Japan, where he belongs to R\&D Department of the Powertrain Control Systems Business Group and has been engaged in the research and development of motors as a Project Director. According to many contributions of new electric rotary machines, he received the title of Certificated Professional from Denso Corporation in 2010. He is also currently working toward the Ph.D. degree from Ibaraki University. Mr. Kusase is a member of the JSAE, IEEJ and IEEE.

Kazumi Kurihara (Senior Member) received the B.E. and M.E. de-

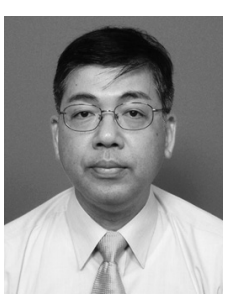
grees from Ibaraki University, Hitachi, Japan, in 1976 and 1978, respectively, and the D.E. degree from Tokyo Institute of Technology, Tokyo, Japan, in 1996. From 1999 to 2000, he was a Visiting Research Fellow with the Memorial University of Newfoundland, St. Johns, NL, Canada. Since 2004, he has been a Professor with the Department of Electrical and Electronic Engineering, Ibaraki University, where he is currently a Special Advisor to the President and a Director of University Education Center. His research interests are permanentmagnet machines, universal motors, hysteresis motors and numerical analysis of the machines. Prof. Kurihara is a member of the IEEE. 